\title{
Pengaruh Kualitas Produk, Kualitas Pelayanan dan Harga Terhadap Kepuasan Pelanggan Pada Kober Mie Setan Cabang Pulau Kawe Denpasar
}

\author{
Ni Putu Rani Sukma Dewi \\ ${ }^{1} \mathrm{Ni}$ Made Rustini \\ ${ }^{2}$ Ni Made Taman Sari \\ Fakultas Ekonomi dan Bisnis Universitas Warmadewa \\ Denpasar, Bali \\ E-mail : ranisukmadewi30@gmail.com
}

\section{How to cite (in APA style):}

Rani Sukma Dewi, Ni Putu. Rustini, Ni Made \& Taman Sari, Ni Made. (2021). Pengaruh Kualitas Produk, Kualitas Pelayanan dan Harga Terhadap Kepuasan Pelanggan Pada Kober Mie Setan Cabang Pulau Kawe Denpasar. Warmadewa Management and Business Journal, 3(1) pp.41-48

\begin{abstract}
ABSTRAKSI
Adapun perumusan masalah dalam penelitian ini adalah bagaimana pengaruh harga terhadap kepuasan pelanggan dan bagiamana pengaruh kualitas produk, kualitas pelayanan dan harga terhadap kepuasan pelanggan pada Kober Mie Setan Cabang Pulau Kawe Denpasar. Tujuan penelitian ini adalah untuk mengetahui pengaruh kualitas produk, kualitas pelayanan dan harga terhadap kepuasan pelanggan pada Kober Mie Setan Cabang Pulau Kawe. Dalam penelitian ini digunakan tiga variabel yang terdiri dari tiga variabel bebas yaitu kualitas produk $\left(\mathrm{X}_{1}\right)$, kualitas pelayanan $\left(\mathrm{X}_{2}\right)$, harga $\left(\mathrm{X}_{3}\right)$, sedangkan variabel terikat yaitu kepuasan pelanggan (Y). Sampel dalam penelitian ini adalah konsumen Kober Mie Setan Cabang Pulau Kawe Denpasar sebanyak 96 orang dijadikan responden. Instrument penelitian di uji menggunakan uji validitas dan uji relibilitas. Teknik analisis data yang dipergunakan adalah uji asumsi klasik meliputi uji normalitas, uji multikolinearitas, dan uji heteroskedastisitas dan kemudian dilanjutkan dengan analisis regresi linier berganda, uji $\mathrm{f}$ dan uji t. Berdasarkan hasil uji $\mathrm{F}$ diperoleh besarnya F-hitung 36,802 yang lebih besar dari F-tabel 2,70 yang berarti secara simultan berpengaruh signifikan terhadap kepuasan pelanggan pada Kober Mie Setan Cabang Pulau Kawe. Berdasarkan hasil uji t untuk variabel kualitas produk diperoleh besarnya t-hitung 3,901 yang lebih besar dari t-tabel 1,986, variabel kualitas pelayanan diperoleh besarnya t-hitung 2,049 yang lebih besar dari t-tabel 1,986, variabel harga diperoleh besarnya t-hitung 4,145 yang lebih besar dari ttabel 1,986, yang berarti kualitas produk, kualitas pelayanan dan harga secara parsial
\end{abstract}



berpengrauh positif dan signifikan terhadap kepuasan pelanggan pada Kober Mie Setan Cabang Pulau Kawe.

Kata kunci : Kualitas Produk, Kualitas Pelayanan, Harga, Kepuasan Pelanggan

\section{A. PENDAHULUAN}

Indonesia merupakan negara yang kaya kuliner yang sudah terkenal sampai ke seluruh dunia, bahkan banyak sekali warga negara asing yang sangat menyukai masakan Indonesia. Salah satu yang menjadi ciri dari masakan indonesia yaitu masakan pedasnya. Untuk memenuhi konsumsi konsumen terhadap makanan pedas, maka saat ini banyak bermunculan restoran atau rumah makan yang menyediakan makanan pedas dengan berbagai level sebagai menu utamanya. Dalam dunia perindustrian makanan, mie merupakan makanan yang cukup digemari oleh masyarakat di Indonesia. Hal ini dapat dilihat dari banyaknya bisnis kuliner yang menggunakan mie sebagai salah satu menu yang ditawarkan.

Hal yang cukup menarik pada objek ini adalah tingginya aktifitas pembelian pada Kober Mie Setan cabang Pulau Kawe dimana para pelanggan tiap harinya rela mengantre panjang untuk membeli makanan pedas ini. Dengan tingginnya tingkat pembelian bisnis kuliner ini dapat dikatakan berhasil dalam menjalankan usaha bisnisnya, namun tidak dapat dipungkiri bahwa suatu bisnis harus memiliki strategi agar dapat mempertahankan bisnisnya serta mampu menjaga keloyalitasan para pelanggan. Agar mampu bertahan serta mengembangkan bisnis tersebut, Kober Mie Setan cabang Pulau Kawe harus mampu bersaing dan menciptakan keunggulan kompetitif pada kualitas layanan yang diberikan, menciptakan kepuasan bagi para pelanggan serta memberikan program yang berguna untuk menunjang kesetiaan para pelanggan Kober Mie Setan cabang Pulau Kawe. Kepuasan pelanggan dapat dilihat melalui sikap pelanggan yang merasa puas atas layanan dan kinerja suatu perusahaan. Pelanggan yang merasa puas dapat dinyatakan melalui sikap mereka setelah merasakan layanan atau produk yang telah mereka terima.

Aspek yang perlu diperhatikan dalam produk adalah kualitas produk. Kualitas produk merupakan pemahaman bahwa produk yang ditawarkan oleh penjual mempunyai nilai jual yang tiedak dimiliki oleh produk pesaing (Nela,2012:5) Sehingga definisi ini dapat dikatakan bahwa seorang penjual telah memberikan kualitas bila penjual telah memenuhi atau melebihi harapan konsumen.

Kepuasan pelanggan merupakan salah satu elemen penting dalam peningkatan kinerja pemasaran dalam suatu perusahaan. Kepuasan yang dirasakan oleh pelanggan dapat meningkatkan intensitas membeli dari pelanggan tersebut. Dengan terciptanya tingkat 
kepuasan pelanggan yang optimal maka mendorong terciptanya loyalitas di benak pelanggan dipenuhi (Nugroho, 2015:162). Kepuasan pelanggan adalah pelanggan yang merasa puas pada produk atau jasa yang dibeli dan digunaknnya akan kembali menggunakan jasa atau produk yang ditawarkan. Kepuasan konsumen tercipta karena kinerja perusahaan sesuai dengan kebutuhan dan keinginan konsumen. Kebutuhan dan keinginan inilah yang bisa disebut harapan konsumen. Jika kinerja perusahaan kurang dari harapan konsumen, maka konsumen merasa kecewa. Jika kinerja perusahaan melebihi harapan konsumen, maka konsumen merasa sangat puas, sehingga dapat menimbulkan loyalitas.

Berdasarkan uraian di atas, maka penulis tertarik untuk mengkaji secara lebih mendalam untuk mengevaluasi betapa pentingnya kualitas produk, kualitas pelayanan dan harga yang diberikan Kober Mie Setan Cabang Pulau Kawe Denpasar kepada konsumen dalam upaya meningkatkan kepuasan pelanggan, maka peneliti akan melakukan penelitian dengan mengambil judul "Pengaruh Kualitas Produk, Kualitas Pelayanan dan Harga Terhadap Kepuasan Pelanggan Pada Kober Mie Setan Cabang Pulau Kawe Denpasar".

\section{B. TINJAUAN PUSTAKA}

1. Pemasaran

Pemasaran merupakan suatu perpaduan dari aktifitas - aktifitas yang saling berhubungan untuk mengetahui kebutuhan konsumen melalui penciptaan, penawaran, dan pertukaran produk dan jasa yang bernilai serta mengembangkan promosi, distribusi, pelayanan, dan harga agar kebutuhan konsumen dapat terpuaskan dengan baik pada tingkat keuntungan tertentu (Sudaryono, 2016:42).

2. Kualitas produk

Kualitas produk adalah kemampuan suatu barang untuk memberikan hasil atau kinerja yang sesuai bahkan melebihi dari apa yang diinginkan pelanggan (Kotler dan Keller, 2015:164). Kualitas produk merupakan proses evaluasi secara keseluruhan kepada pelanggan atas perbaikan kinerja suatu produk (Mowen,2014:61).

3. Kualitas pelayanan 
Kualitas pelayanan adalah suatu aktivitas atau serangkaian aktivitas yang tidak berwujud yang terjadi sebagai akibat adanya interaksi antara konsumen dengan karyawan atau hal - hal lain yang disediakan oleh perusahan pemberin pelayanan yang dimaksudkan untuk memecahkan permasalahan konsumen/pelanggan (Kurniawan Albert, 2014:135).

\section{Harga}

Harga adalah satuan moneter atas ukuran lainnya (termasuk barang dan jasa lainnya) yang ditukarkan agar memproleh hak kepemilikan atau penggunaan suatu barang atau jasa (Tjiptono, 2014:2015).

5. Kepuasan Pelanggan

Menurut Kotler dalam buku Sunyoto (2013:35), kepuasan konsumen adalah tingkat perasaan seseorang setelah membandingkan (kinerja atau hasil) yang dirasakan dibandingkan dengan harapannya. Konsumen dapat mengalami salah satu dari tiga tingkat kepuasan umum yaitu kalau kinerja di bawah harapan, konsumen akan merasa kecewa tetapi jika kinerja sesuai dengan harapan pelangganakan merasa puas dan apabila kinerja bisa melebihi harapan maka pelanggan akan merasakan sangat puas senang atau gembira.

Menurut Lovelock dan Wirtz yang dikutip oleh Fandy Tjiptono (2016:74) Kepuasan adalah suatu sikap yang diputuskan berdasarkan pengalaman yang didapatkan.

Hipotesis adalah dugaan sementara yang kebenarannya masih harus dilakukan pengujian. Berdasarkan masalah pokok dan tujuan penelitian, maka hipotesis yang dikemukakan adalah :

Adapun hipotesis dalam penelitian ini adalah :

1. Kualitas produk berpengaruh positif dan signifikan terhadap kepuasan pelanggan pada Kober Mie Setan Cabang Pulau Kawe.

2. Kualitas pelayanan berpengaruh positif dan signifikan terhadap kepuasan pelanggan pada Kober Mie Setan Cabang Pulau Kawe.

3. Harga berpengaruh positif dan signifikan terhadap kepuasan pelanggan pada Kober Mie Setan Cabang Pulau Kawe.

4. Kualitas produk, kualitas pelayanan dan harga berpengaruh terhadap kepuasan pelanggan pada Kober Mie Setan Cabang Pulau Kawe. 


\section{METODE PENELITIAN}

Penelitian ini dilakukan pada Kober Mie Setan Cabang Pulau Kawe Denpasar yang berlokasi di Jalan Pulau Kawe, Dangin Puri Klod, Kec. Denpasar Barat, Kota Denpasar, Bali. Dan yang menjadi obyek penelitian ini adalah kualitas produk, kualitas pelayanan, harga dan kepuasan pelanggan. Jumlah sampel yang diambil pada penelitian ini adalah sebanyak 96 orang responden. Pengambilan sampel dalam penelitian ini adalah menggunakan Accidental Sampling.

Metode Pengumpulan Data dalam penelitian ini yaitu dengan Observasi, Wawancara, Studi Dokumentasi, serta Kuisioner. Teknik Analisis Data Uji Validitas dan Reliabilitas, Uji reliabilitas, Uji Asumsi Klasik, Analisis Regresi Linier Berganda, Uji Statistik F (F-test), Uji Statistik t (t-test).

\section{HASIL DAN PEMBAHASAN}

\section{Pengujian Instrumen Penelitian}

Uji validitas yang dimana nilai skor total Pearson Correlation masing- masing instrumen berada diatas 0,30 dan memiliki nilai signifikansi yang lebih kecil dari $5 \%(0,05)$, Serta uji reliabilitas pada masing-masing variabel berada pada titik diatas 0,60 yang ditunjukkan pada hasil Cronbach's Alpha.

\section{Uji Asumsi Klasik}

Berdasarkan uji normalitas dengan menggunakan One-Sample Kolmogorov-Smirnov Test bahwa besarnya nilai Kolmogorov-Smirnov sebesar 0,079 > 0,05 maka $\mathrm{H}_{\mathrm{o}}$ diterima yang mengindikasikan bahwa data yang digunakan pada penelitian ini terdistribusi normal. Uji multikolinearitas dapat disimpulkan bahwa model uji tidak terdeteksi kasus multikolinearitas karena Tolerance dan VIF lebih besar dari 0,1 dan lebih kecil dari 10 . Jadi, Pengujian heteroskedastisitas model memiliki nilai signifikansi lebih besar dari 0,05 (5\%). Hal ini menunjukkan bahwa variabel bebas yang digunakan pada penelitian ini tidak berpengaruh secara signifikan terhadap variabel terikatnya yaitu absolute error, maka dari itu, penelitian ini bebas dari gejala heteroskedastisitas.

\section{Analisis Regresi Linier Berganda}

Berdasarkan Tabel 16 dapat ditulis persamaan regresi linear berganda sebagai berikut. $Y=-3,613+0,408 X_{1}+0,287 X_{2}+0,491 X_{3}$ Persamaan regresi linear berganda tersebut 
menunjukkan arah masing-masing variabel bebas terhadap variabel terikatnya yaitu Kepuasan Pelanggan.

\section{Uji F}

Berdasarkan Uji $\mathrm{F}$ diketahui $\mathrm{F}_{\text {hitung }}(36,802)>\mathrm{F}_{\text {tabel }} \quad(2,70)$ dengan nilai signifikansi F adalah $0,000<0,05$, maka $\mathrm{H}_{0}$ ditolak. Hal ini berarti bahwa variabel kualitas produk $\left(\mathrm{X}_{1}\right)$ kualitas pelayanan $\left(\mathrm{X}_{2}\right)$ dan harga $\left(\mathrm{X}_{3}\right)$ secara simultan berpengaruh signifikan terhadap kepuasan pelanggan (Y) pada Kober Mie Setan Cabang Pulau Kawe.

\section{Hasil Uji t}

a. Berdasarkan hasil analisis diperoleh nilai $t_{\text {hitung }}(3,901)>t_{\text {tabel }}(1,986)$ dengan tingkat signifikansi $0,000<0,05$, sehingga $\mathrm{H}_{0}$ ditolak dan $\mathrm{H}_{\mathrm{a}}$ diterima yang berarti bahwa variabel kualitas produk $\left(\mathrm{X}_{1}\right)$ berpengaruh positif signifikan terhadap kepuasan pelanggan $(Y)$. Koefisien regresi $\beta 1\left(\mathrm{X}_{1}\right)$ sebesar 0,408 , menunjukkan bahwa semakin baik kualitas produk maka kepuasan pelanggan semakin meningkat.

b. Berdasarkan hasil analisis diperoleh bahwa $t_{\text {hitung }}(2,409)>t_{\text {tabel }}(1,986)$ dengan tingkat signifikansi $0,018<0,05$, sehingga $\mathrm{H}_{0}$ ditolak dan $\mathrm{H}_{\mathrm{a}}$ diterima yang berarti bahwa variabel kualitas pelayanan $\left(\mathrm{X}_{2}\right)$ berpengaruh positif signifikan terhadap kepuasan pelanggan $(\mathrm{Y})$. Koefisien regresi $\beta 2\left(\mathrm{X}_{2}\right)$ sebesar 0,287 menunjukkan bahwa semakin baik kualitas pelayanan maka kepuasan pelanggan semakin meningkat.

c. Berdasarkan hasil analisis dijelaskan bahwa $t_{\text {hitung }}(4,145)>t_{\text {tabel }}(1,986)$ dengan tingkat signifikansi $0,000<0,05$, sehingga $\mathrm{H}_{0}$ ditolak dan $\mathrm{H}_{\mathrm{a}}$ diterima yang berarti bahwa variabel harga $\left(\mathrm{X}_{3}\right)$ berpengaruh positif signifikan terhadap kepuasan pelanggan $(\mathrm{Y})$. Koefisien regresi $\beta 3\left(\mathrm{X}_{3}\right)$ sebesar 0,491 menunjukkan bahwa semakin sesuai harga maka kepuasan pelanggan (Y) semakin meningkat.

\section{E. PENUTUP}

a. Simpulan

Berdasarkan hasil analisis data dan pembahasan, maka didapat simpulan hasil penelitian adalah sebagai berikut : 
1. Kualitas produk berpengaruh positif dan signifikan terhadap kepuasan pelanggan pada Kober Mie Setan Pulau Kawe . Hal ini berarti bahwa semakin baik kualitas produk maka kepuasan pelanggan semakin meningkat pada Kober Mie Setan Cabang Pulau Kawe.

2. Kualitas pelayanan berpengaruh positif dan signifikan terhadap kepuasan pelanggan pada Kober Mie Setan Pulau Kawe. Hal ini berarti bahwa semakin baik kualitas pelayanan maka kepuasan pelanggan semakin meningkat pada Kober Mie Setan Cabang Pulau Kawe.

3. Harga berpengaruh positif dan signifikan terhadap kepuasan pelanggan pada Kober Mie Setan Cabang Pulau Kawe. Hal ini berarti bahwa semakin sesuai harga maka kepuasan pelanggan semakin meningkat pada Kober Mie Setan Cabang Pulau Kawe.

4. Kualitas produk, kualitas pelayanan dan harga berpengaruh signifikan terhadap kepuasan pelanggan pada Kober Mie Setan Cabang Pulau Kawe.

b. Saran

Berdasarkan hasil yang diperoleh kualitas produk, kualitas pelayanan dan harga memiliki pengaruh yang positif dan signifikan terhadap kepuasan pelanggan secara simultan. Untuk pengembangan perusahaan dalam menghadapi persaingan maka Kober Mie Setan Cabang Pulau Kawe sebaiknya:

1. Dari kualitas produk sebaiknya membuat cita rasa yang konsisten sesuai dengan keinginan pelanggan agar karyawan tidak merasa kecewa dengan rasa makanan yang dihidangkan dan cita rasa tetap terjaga dengan baik.

2. Dari kualitas pelayanan diharapkan lebih mempercepat proses pelayanan agar pelanggan tidak merasa jenuh menunggu pesanan datang.

3. Dari harga diharapkan memperbaiki kualitas makanan agar sesuai dengan harga yang ditetapkan, agar minat pelanggan untuk berkunjung kembali ke Kober Mie Setan Cabang Pulau Kawe tetap terjaga. Dengan demikian, kepuasan pelanggan pada Kober Mie Setan Cabang Pulau Kawe akan tetap terjaga dengan baik.

4. Bagi penelitian selanjutnya diharapkan mampu menambah variabel- variabel yang dapat mempengaruhi kepuasan pelanggan serta mampu untuk memperluas ruang lingkup penelitian atau dapat juga mengganti lokasi penelitian yang tidak hanya terfokus 
pada suatu lokasi penelitian, sehingga memberikan suatu pandangan yang lebih dan mampu diimplementasikan secara umum.

\section{F. DAFTAR PUSTAKA}

Ayu Yuni Darma Ni Putu. (2019). Pengaruh Kualitas Pelayanan, Kualitas Produk, dan Harga Terhadap Keputusan Pembelian Wine Pada CV Agung Wine Shop Sanur. Denpasar: Universitas Warmadewa.

Hasan, A. (2014). Marketing dan Kasus-kasus Pilihan, Cetakan Kedua. CAPS(Center for Academic Publishing Service).

Ikhprastyo, A. R. (2018). Pengaruh Kualitas Pelayanan, Kualitas Produk Dan Promosi Terhadap Loyalitas Pelanggan Melalui Kepuasan Pelanggan Di Mister Geprek

Bandar Lampung. In Skripsi (Issue Fakultas Keguruan dan Ilmu Pendidikan).

Universitas Lampung.

Irnandha, A. (2016). Pengaruh Kualitas Layanan Terhadap Loyalitas Pelanggan Yang

Dimediasi Oleh Kepuasan Pelanggan Jasa Pengiriman Jalur Darat. Jurnal Manajemen

Pemasaran. Yogyakarta: Universitas Negeri Yogyakarta.

Kotler, Philip \& Keller, K. L. (2011). Manajemen Pemasaran. Jakarta: Erlangga.

Kotler, Philip dan Amstrong, G. (2014). Prinsip - Prinsip Pemasaran jilid 1, Edisi keduabelas (P. P. G. A. Pratama (ed.)).

Kurniawan, D. (2019). Pengaruh Kualitas Produk Dan Harga Terhadap Kepuasan Konsumen Pada CV. Bali Bidadari Batik Denpasar.

Putra, D. (2019). Pengaruh Kualitas Produk Dan Kualitas Pelayanan terhadap Kepuasan Dan Loyalitas Pelanggan (Studi Pada Toko Pengecer Pakaian Dan Aksesoris "Fashion Market"). Denpasar: Universitas Warmadewa.

Sugiyono. (2016). Statistika Untuk Penelitian, Edisi ke-27. Bandung. Penerbit Alfabeta. Tjiptono, F. (2012). Strategi Pemasaran. Edisi Kedua. Penerbit Andi Offest. Yogyakarta. 